\title{
The effect of clipping on the growth and miserotoxin content of Columbia milkvetch
}

\author{
W. MAJAK, D.A. QUINTON, H.E. DOUWES, J.W. HALL, AND A.D. MUIR
}

\begin{abstract}
The growth and miserotoxin content of Columbia milkvetch (Astragalus miser Dougl. var. serotinus (Gray) Barneby) were examined in clipping trials at 2 rangeland sites in southern British Columbia during 1984 and 1986 . Growth was determined by measuring the freeze-dried weight of each plant and miserotoxin levels were estimated by a rapid screening method that simplified sample preparation for spectrophotometric determination. In both years and at both sites, growth and toxicity were substantially reduced in response to early clipping in the spring. In comparison to untreated plants, the aboveground biomass of clipped plants was reduced by at least 50\% during a 6-wk period of regrowth. A similar reduction was also observed in the miserotoxin content of clipped plants. The results indicate that early grazing may reduce the potential hazard of timber milkvetch to livestock
\end{abstract}

\section{Key Words: poisonous plants, miserotoxin}

Miserotoxin, 3-nitro-l-propyl- $\beta$-D-glucopyranoside, has been positively identified in 10 species of Astragalus and its aglycone moiety, 3-nitropropanol, has been detected in 49 additional species of the leguminous genus (Stermitz and Yost 1978, Williams, 1982, Williams and Gómez-Sosa 1986). These species occur primarily on rangelands in the temperate regions of North and South America and some are found in Asia. In ruminants, where acute or chronic poisonings can occur from Astragalus ingestion, miserotoxin is rapidly hydrolyzed to 3-nitropropanol by microbial enzymes of the rumen and the aglycone is readily absorbed from the rumen (Pass et al, Majak et al. 1984). After absorption, the nitroalcohol is converted to 3-nitropropionic acid (Muir et al. 1984), an oxidation that appears to be catalyzed by alcohol dehydrogenase (Pass et al. 1985). 3-Nitropropionic acid, which also occurs in higher plants and fungi, is a potential inhibitor of mitochondrial enzymes essential to respiration (Gustine 1983, Gould et al. 1985).

In southern British Columbia high levels of miserotoxin are synthesized in Columbia milkvetch (Astragalus miser Dougl. serotinus (Gray) Barneby) and the glycoside can account for more than $5 \%$ of the herbage dry matter. The dynamic changes that occur in miserotoxin concentrations of Columbia milkvetch with advancing stages of growth and the effects of rainfall, nitrogen fertilizer, and sunlight on the levels of the glycoside have been documented (Majak and Wikeem 1986, Majak et al. 1977).

To further elucidate and predict the toxicity of Columbia milkvetch to livestock we determined the effect of early clipping on the growth of Columbia milkvetch and on the synthesis of miserotoxin. This research was conducted to indicate whether toxicity to livestock would be enhanced or diminished in response to grazing the plant at the bud stage of growth when the toxin concentration is high but the biomass is relatively small. A rapid screening method was also developed that simplified the spectrophotometric determination of miserotoxin in Columbia milkvetch and this was compared to an analytical procedure utilizing high pressure liquid chromatography (HPLC).

\footnotetext{
Authors are biochemist, range management scientist, and research assistant, Agriculture Canada, Research Station, 3015 Ord Road, Kamloops, B.C. V2B 8A9; statistician, Agriculture Canada, Research Station, 6660 N.W. Marine Drive, Vancouver, B.C. V6T IX2; and research consultant, c/o Agriculture Canada, Research Station, 3015 Ord Road, Kamloops, B.C. V2B 8A9.

The authors gratefully acknowledge the technical assistance of Ruth McDiarmid, Alice Mui, Wendy Pepper, and Brenda Pink.

Manuscript accepted 13 August 1987.
}

Materials and Methods

The clipping trials were conducted at 2 sites near Lac du Bois, 11 $\mathrm{km}$ north of Kamloops B.C. The sites were located on a rough fescue (Festuca scabrella Torr.) grassland with a bluebunch wheatgrass (Agropyron spicatum (Pursh) S. \& S.)-rough fescue community (van Ryswyk et al. 1966) and in a Douglas fir (Pseudotsuga menziesii (Mirb.) Franco) forest with a Douglas fir-pinegrass (Calamagrostis rubescens Buckl.) community (Tisdale and McLean 1957).

Groups of Columbia milkvetch plants were collected at each site at weekly intervals for 7 weeks during May 22-July 3 in 1984. Plants within a group were chosen randomly and each plant was assigned a colored stake to identify the clipping treatment. Six groups of 20 plants were harvested on the first day of the trial (a control group and 5 groups which would be subjected to clipping again). The aerial portion of each plant was excised at the base just above the crown. At weeks 3, 4, 5, 6, and 7 one group of previously clipped plants and a new control group of 20 plants were harvested. The experimental design is illustrated in Table 1 . In 1986 the plants

Table 1. Experimental design for collecting Columbia milkvetch control groups (C) and treatment groups after the first clipping $\left(T_{1}\right)$ and the second clipping $\left(\mathrm{T}_{2}\right)$. Each group contuined 20 plants.

\begin{tabular}{lllllllll}
\hline \hline $\begin{array}{l}\text { Regrowth } \\
\text { period } \\
\text { (wk) }\end{array}$ & \multicolumn{6}{c}{ Sampling date } \\
\cline { 2 - 8 } & 22 & May & 29 May & 5 June & 12 June & 19 June & 26 June & 3 July \\
\hline 0 & C & C & C & C & C & C & C \\
2 & $T_{1}$ & & $T_{2}$ & & & & \\
3 & $T_{1}$ & & & $T_{2}$ & & & \\
4 & $T_{1}$ & & & & $T_{2}$ & & \\
5 & $T_{1}$ & & & & & $T_{2}$ & \\
6 & $T_{1}$ & & & & & & $T_{2}$ \\
\hline
\end{tabular}

were collected during the same time period but the design was modified slightly. The size (basal area $\times$ height) of 240 plants at each site was determined before clipping started. Plants were then sorted into 20 blocks with the plants in each block being similar in size. One plant from each block was then assigned to each of the 12 groups as in a randomized complete block experiment.

The simplified procedure for estimating miserotoxin colorimetrically was carried out as follows. Freshly collected plants were weighed, frozen, freeze-dried and weighed again to determine percent dry matter and the biomass. The individual plant samples were ground to pass a $1-\mathrm{mm}$ screen in a Wiley mill. A subsample $(0.3 \mathrm{~g})$ was extracted with $50 \mathrm{ml} 0.2 \mathrm{M}$ phosphate buffer (pH 6.4) for $20 \mathrm{~min}$ on an orbital shaker. When $<0.3 \mathrm{~g}$ was available, the entire sample was extracted in $25 \mathrm{ml}$ of buffer. For reproducible determinations, the minimum sample size for extraction was deduced to be $25 \mathrm{mg}$. The extract was centrifuged at $28,000 \times \mathrm{g}$ for $15 \mathrm{~min}$ at $0^{\circ} \mathrm{C}$, the supernatant was transferred to vials and these were stored at $2^{\circ} \mathrm{C}$ with an added drop of chloroform to inhibit microbial growth. The extraction procedure was judged to be complete because re-extraction of the pellet yielded only trace quantities of the toxin. An aliquot of the supernatant $(1 \mathrm{ml})$ was diluted with water $(35 \mathrm{ml})$, combined with $\mathrm{N} \mathrm{NaOH}(0.65 \mathrm{ml})$ and then diazotized p-nitroaniline $(1 \mathrm{ml})$. The volume was adjusted to 
$50 \mathrm{ml}$ and the derivatized miserotoxin was determined spectrophotometrically at $405 \mathrm{~nm}$ (Majak and Clark 1980). Aliquots in excess of $2 \mathrm{ml}$ could not be used because the increased amount of buffer altered the $\mathrm{pH}$ of the reaction mixture.

To check the accuracy of the colorimetric method, miserotoxin was also determined by HPLC and the 2 methods were compared. Protein was precipitated prior to HPLC by treating an aliquot of the supernatant with 1 volume of aqueous $10 \% \mathrm{ZnSO}_{4}$ and a half volume of $0.5 \mathrm{~N} \mathrm{NaOH}$. The mixture was chilled for $0.5 \mathrm{~h}$ at $2^{\circ} \mathrm{C}$, centrifuged at $28,000 \times \mathrm{g}$ for $10 \mathrm{~min}$ at $0^{\circ} \mathrm{C}$, and a subsample of the supernatant was analyzed by HPLC. Baseline separation of miserotoxin was achieved on a Varian reverse phase Micropak MCH5 column $(30 \mathrm{~cm} \times 4 \mathrm{~mm})$ utilizing aqueous $0.1 \%$ orthophosphoric acid as the mobile phase, and the glycoside was quantified as described previously (Muir and Majak 1984). The retention times for miserotoxin, 3-nitropropanol, and 3-nitropropionic acid were $15.7,12.1$, and $8.5 \mathrm{~min}$, respectively.

Analyses of variance were used to examine the effects of clipping on plant weight ( $\mathrm{g}$ of dry matter), percent miserotoxin and on the amount of toxin per plant. A logarithm transformation was used on the amount of toxin per plant to stabilize the variance. For plotting relationships with time in 1984, exponential curves were fitted using non-linear regression (SAS NLIN). Quadratic curves were fitted in 1986 using polynomial regression (SAS GLM).

\section{Results and Discussion}

The rapid screening method for misertoxin determination in Columbia milkvetch was checked against the analytical HPLC procedure. In both years there was good agreement between the methods $r=0.91, n=131$ in 1984 and $r=0.98, n=58$ in 1986). The better agreement in 1986 was attributed to the protein precipitation step which improved the HPLC resolution. This clean-up step was not used in 1984. The screening method yielded slightly higher values for miserotoxin (as a percentage of the dry matter) than the HPLC procedure. In 1984, the average difference between the methods was $0.54 \%$ miserotoxin and its $95 \%$ confidence interval was $\pm 0.32 \%$. In 1986 , the average difference was $0.16 \%$ and the $95 \%$ confidence interval was $\pm 0.66 \%$. With the simplified colorimetric procedure, an experienced technician analyzed $\mathbf{4 0}$ freezedried Columbia milkvetch samples per day, a number that would be unfeasible to determine by normal chromatographic procedures. Although other screening methods are available for nitrocompounds, these are not suitable for the analysis of miserotoxin in Columbia milkvetch (Majak et al. 1983). It should be emphasized that the screening method described here gives an estimate of the glycoside level and it should be used in conjunction with a quantitative, analytical procedure which would continually monitor its precision.

The analyses of variance revealed the following general trends. The aboveground weights of control plants were much larger and more variable than those of the clipped plants. Control plants ranged in size from $1 \mathrm{~g}$ dry matter/plant at week 1 to $7 \mathrm{~g} /$ plant at week 7. The regrowth of clipped plants showed a gradual increase to an average weight of $1 \mathrm{~g} \mathrm{dry}$ matter/plant at week 7 . Control plants were larger at the grassland site than at the forest site but the average amount of regrowth was approximately the same at both locations. The synthesis and accumulation of miserotoxin in each plant followed a pattern similar to the change in the biomass, with control plants showing much larger amounts of the glycoside than clipped ones. The amount of miserotoxin in control plants ranged from an average of $40 \mathrm{mg} /$ plant at week 1 to as high as 278 $\mathrm{mg} /$ plant at week 7 . In clipped plants, there was a rapid synthesis of miserotoxin during the initial period of growth but then the rate of glycoside accumulation declined and maximum values for miserotoxin varied from an average of 35 to $75 \mathrm{mg} /$ plant. When miserotoxin levels were expressed as a percentage of the dry matter however, higher concentrations of the glycoside were found in the biomass of clipped plants than in that of the control plants. This effect was enhanced at the grassland site where average concentrations of the toxin in regrowth tissue could be as high as $11 \%$ compared to $6 \%$ for the forest site. The average concentration of miserotoxin in control plants declined from approximately $5 \%$ to $4 \%$ during the 6 wk period of growth. However, average concentrations of the glycoside (6 to 8\%) were elevated in regrowth tissue even in the final weeks of the experiment.

The above results indicate that conclusions about the relative toxicity and the potential hazard of normal growth and regrowth to livestock will differ depending on whether toxicity is measured by miserotoxin concentration or by total miserotoxin accumulation per plant. If the grazing pattern is strictly selective, and the animal shows a high preference for the more succulent regrowth of Columbia milkvetch, then regrowth tissue may be more hazardous because of the higher concentration of the toxin. However, the biomass of the regrowth was relatively small $(0.2$ to $1.0 \mathrm{~g}$ dry matter/plant) in these studies and would be relatively unavailable or inaccessible. Thus, if the grazing pattern is determined by forage availability, then normal growth would be more toxic because of its greater biomass and the associated greater accumulation of toxin.

Detailed results from the 1984 clipping trial are shown in Figures 1 and 2 . The dry matter yields (Fig. 1) and the miserotoxin amounts (Fig. 2) in control plants were significantly higher than in clipped plants. For example, 2 weeks after the initial clipping the average dry matter content of control plants exceeded $2 \mathrm{~g}$ but measurable regrowth of Columbia milkvetch was not detected on the grassland site and it was only $10 \%$ of that in the controls on the forest site. The miserotoxin accumulations followed a similar trend and the total content in the regrowth biomass was significantly lower than that of the controls (Fig. 2).

The variability in the dry matter content of control plants, especially on the grassland site (Fig. 1) during 1984 can be largely attributed to imperfections in the sampling procedure. During the

Table 2. Average miserotoxin concentration (\%) in Columbia milkvetch control groups (C) and treatments groups ( $\left.T_{2}\right)$ at 2 sites during 1984 and 1986 , data expresced on a dry matter basis.

\begin{tabular}{|c|c|c|c|c|c|c|c|c|}
\hline \multirow[b]{3}{*}{ Date } & \multicolumn{4}{|c|}{1984} & \multicolumn{4}{|c|}{1986} \\
\hline & \multicolumn{2}{|c|}{ Grassland site } & \multicolumn{2}{|c|}{ Forest site } & \multicolumn{2}{|c|}{ Grassland site } & \multicolumn{2}{|c|}{ Forest site } \\
\hline & C & $T_{2}$ & C & $T_{2}$ & C & $\mathbf{T}_{2}$ & C & $T_{2}$ \\
\hline & & & & $-1 \%$ & in)-_- & & & \\
\hline 22 May & 4.74 & - & 4.46 & - & 5.19 & - & 4.53 & - \\
\hline 29 May & 5.32 & - & 4.52 & - & 5.12 & - & 4.78 & - \\
\hline 5 June & 5.26 & - & 5.28 & 4.33 & 4.70 & 8.51 & 4.88 & 6.26 \\
\hline 12 June & 4.66 & 3.78 & 5.26 & 3.91 & 4.91 & 11.12 & 4.07 & 5.88 \\
\hline 19 June & 5.02 & 7.50 & 4.42 & 6.03 & 4.72 & 9.85 & 4.12 & 5.90 \\
\hline 26 June & 5.12 & 8.00 & 3.56 & 5.61 & 4.18 & 9.98 & 4.00 & 6.09 \\
\hline 3 July & 4.61 & 6.96 & 3.27 & 4.47 & 4.06 & 9.74 & 3.68 & 5.89 \\
\hline SE & & & & & & & & \\
\hline
\end{tabular}




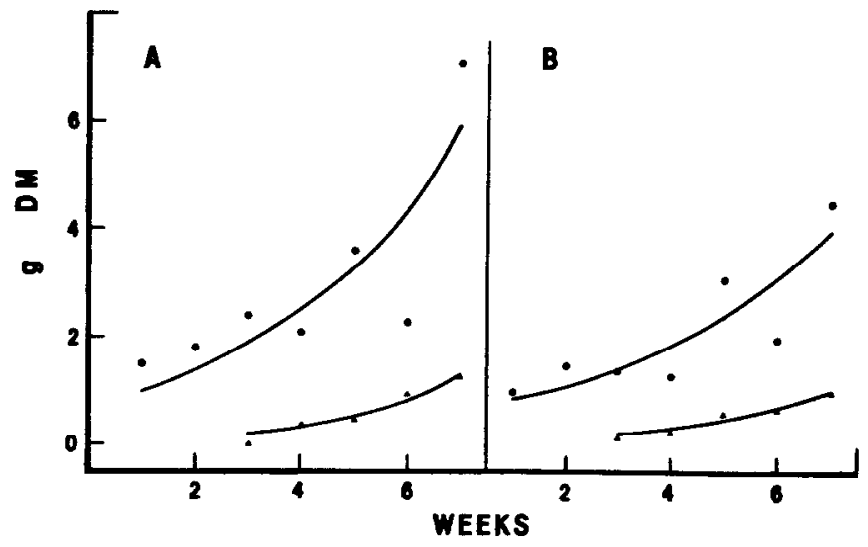

Fit. 1. Effects of clipping on the average dry matter (DM) content of Columbia milkvetch plants at the grassland site $(A)$ and at the forest site (B) during 1984. Control plants are indicated with circles and clipped plants with triangles. $S E(D M)=0.294$

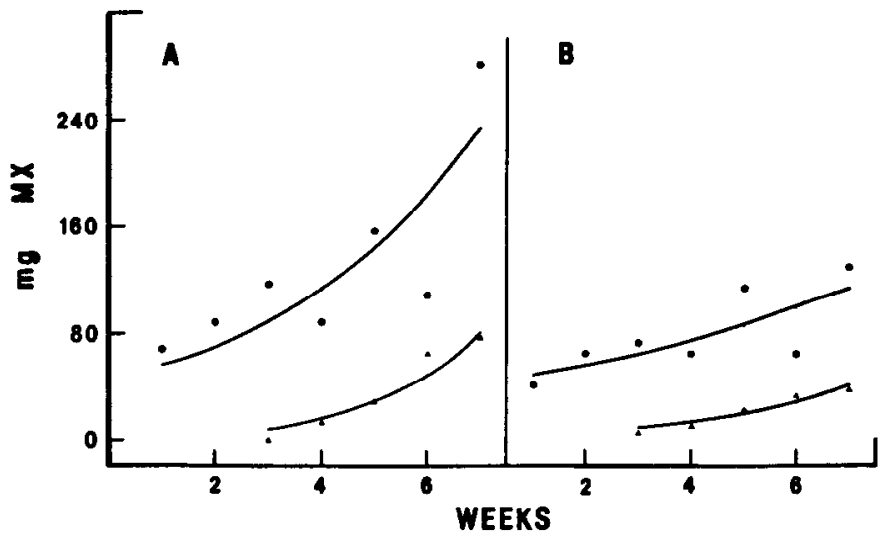

Fig. 2. Effects of clipping on the average amoung ( $\overline{\mathbf{x}})$ of miserotoxin $(M X)$ in Columbia milkvetch plants at the grassland site $(A)$ and at the forest site (B) during 1984. Control plants are indicated with circles and clipped plants with triangles. $S E(M X)=0.145 \bar{x}$.

fifth harvest for example, the collector selected a preponderance of large plants $>\mathbf{3}$ g dry matter). To eliminate this problem, plant sizes were predetermined in 1986 and experimental groups were assigned a more even distribution of biomass.

The slow initial rate of growth for Columbia milkvetch (Fig. 1) can be mainly attributed to the unseasonable weather conditions in May 1984. This month established a record as the coldest May in 92 years of continuous record (Atmospheric Environment Service 1984). The slow rate of growth was also reflected in the delayed phenological development of the plant. In 6 weeks, the plant advanced only from the bud stage of growth to full bloom with some development of immature pods. In contrast, the month of May 1986 had normal temperatures and rainfall (Atmospheric Environment Service 1986) and the plants grew much more rapidly (Fig. 3). In 6 weeks in 1986, the plants advanced from the bud stage of growth, through the mature pod stage, and partly into senescence as evidenced by the decrease in biomass (Fig. 3). Temperatures during June of 1984 and 1986 were also much closer to normal than the extreme of May 1984.

In agreement with the results for 1984, the control plants in 1986 also yielded significantly higher dry matter than the clipped plants (Fig. 3). During the fourth to seventh week at the forest site, the dry matter content of the control plants was approximately 4 times greater than the biomass of the clipped plants and a similar trend was observed at the grassland site. The changes in miserotoxin content in the control plants appeared to follow the growth cycle with increases (synthesis) occurring at early stages of growth and

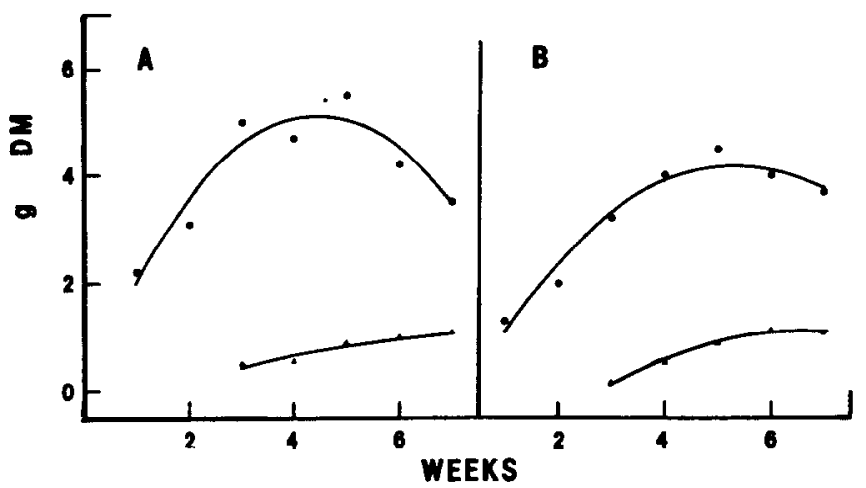

Fig. 3. Effects of clipping on the average dry matter (DM) content of Columbia milkvetch plants at the grassland site $(A)$ and at the forest site (B) during 1986. Control plants are indicated with circles and clipped plants with triangles. $S E(D M)=0.420$.

decreases (catabolism) during senescence (Fig. 4). The regrowth had a much higher toxin content in 1986 than in 1984 (Fig. 2and 4) and this can be partly attributed to the enhanced growth but mainly to the higher percentage of miserotoxin in the biomass of 1986 (Table 2). On the grassland site, the average toxin concentrations in regrowth tissue were $9.84 \%$ and $6.56 \%$ for 1986 and 1984 , respectively. On the forest site, the comparable levels were $6.00 \%$

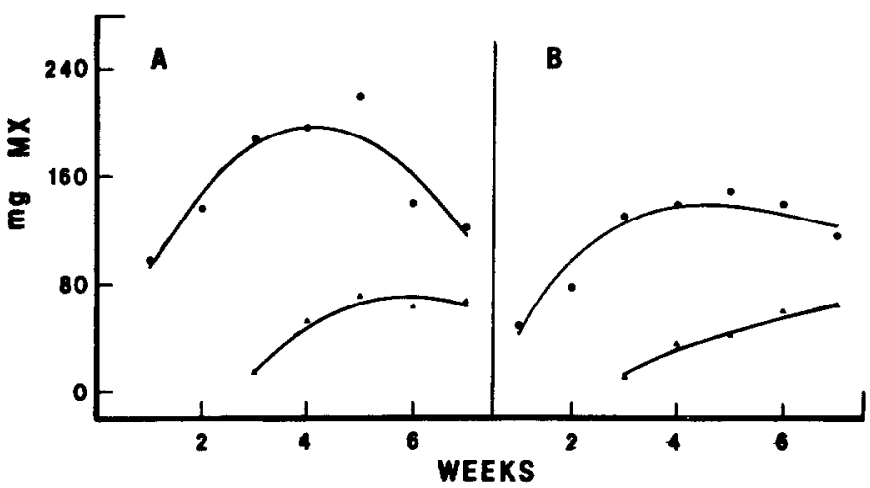

Fig. 4. Effects of clipping on the average amount $(\bar{x})$ of miserotoxin (MX) in Columbia milkvetch plants at the grassland site $(A)$ and at the forest site $(B)$ during 1986. Control plants are indicated with circles and clipped plants with triangles. $S E(M X)=0.153 \bar{x}$.

and $4.87 \%$ for 1986 and 1984 . In spite of the higher percentages (on a dry matter basis), the average quantity of toxin per clipped plant remained significantly lower than the amount in control plants (Fig. 2 and 4). Towards the end of the growth cycle, the amount of toxin in treatment plants was approximately $50 \%$ lower than in control plants at the forest site and $40 \%$ lower at the grassland site. In control plants during 1986, toxin concentration showed a gradual decline with advancing stages of growth (Table 2) similar to that observed in earlier studies (Majak and Wikeem 1986). The decline is not as apparent in 1984 due to the unusual growing season. The importance of this decline in miserotoxin concentration should not be misconstrued however. The data shown in Figures 2 and 4 clearly indicate that more toxin can become available with advancing stages of growth and, depending on feeding habits, the total amount rather than the concentration may govern the toxicity to animals.

In summary, these studies show that early clipping can substantially reduce biomass and total toxin content in Columbia milkvetch. It remains to be shown whether early grazing of Columbia milkvetch in spring will achieve the same results. Nevertheless, the data clearly indicate that the potential hazard to livestock can be 
significantly altered and this was demonstrated in 2 different growing seasons.

\section{Literature Cited}

Atmospheric Environment Service. 1984, 1986. Monthly record. Meteorological observations in western Canada. May, June. Environment Canada, Atmos. Environ. Serv. Downsview, Ontario.

Gustine, D.L., and B.G. Moyer. 1983. Review of mechanisms of toxicity of 3-nitropropanoic acid in nonruminant animals, p. 736-738. In: J.A. Smith and V.W. Hays (eds.), Proc. XIV Inter. Grassland Congr. Westview Press, Boulder, Colo.

Gould, D.H., M.P. Wilaon, and D.W. Hamar. 1985. Brain enzyme and clinical alterations induced in rats and mice by nitroaliphatic toxicants. Toxicol. Lett. 27:83-89.

Majak, W., and L.J. Clark. 1980. Metabolism of aliphatic nitro compounds in bovine rumen fluid. Can. J. Anim. Sci. 60:319-325.

Majak, W., S.G. Lindquist, and R.E. McDiarmid. 1983. A simple method for purification and determination of miserotoxin. J. Agr. Food Chem. 31:650-652.

Majak, W., P.D. Parkinson, R.J. Williams, N.E. Looney, and A.L. van Ryswyk. 1977. The effect of light and moisture on Columbia milkvetch toxicity in lodgepole pine forests. J. Range Manage. 30:423-427.

Majak, W., M.A. Pass, A.D. Muir, and L.M. Rode. 1984. Absorption of 3-nitro-propanol (miserotoxin aglycone) from the compound stomach of cattle. Toxicol. Lett. 23:9-15.

Majak, W., and B.M. Wikeem. 1986. Miserotoxin levels in fertilized Astragalus miser var. serotinus. J. Range Manage. 39:130-131.
Muir, A.D., and W. Majak. 1984. Quantitative determination of 3nitropropionic acid and 3-nitropropanol in plasma by HPLC. Toxicol. Lett. 20:133-136.

Muir, A.D., W. Majak, M.A. Pass, and G.S. Yost. 1984. Conversion of 3-nitro-propanol (miserotoxin aglycone) to 3-nitropropionic acid in cattle and sheep. Toxicol. Lett. 20:137-141.

Pass, M.A., W. Majak, A.D. Muir, and G.S. Yost. 1984. Absorption of 3-nitro-propanol and 3-nitropropionic acid from the digestive system of sheep. Toxicol. Lett. 23:1-7.

Pass, M.A., A.D. Mulr, W. Majak, and G.S. Yost. 1985. Effect of alcohol and aldehyde dehydrogenase inhibitors on the toxicity of 3-nitropropanol in rats. Toxicol. Appl. Pharmacol. 78:310-315.

van Ryswyk, A.L., A. McLean, and L.S. Marchand. 1966. The climate, native vegetation, and soils of some grasslands at different elevations in British Columbia. Can. J. Plant Sci. 46:35-50.

Stermitz, F.R., and G.S. Yost. 1978. Analysis and characterization of nitro compounds from Astragalus species, p. 371-378. In: R.F. Keeler, K.R. Van Kampen, and L.F. James (eds.), Effects of poisonous plants on livestock, Academic Press, New York.

Tisdale, E.W., and A. McLean. 1957. The Douglas fir zone of southern British Columbia. Ecol. Monogr. 27:247-266.

Williams, M.C. 1982. 3-Nitropropionic acid and 3-nitro-1-propanol in species of Astragalus. Can. J. Bot. 60:1956-1963.

Williams, M.C., and E. Gómez-Sosa. 1986. Toxic nitro compounds in species of Astragalus (Fabaceae) in Argentina. J. Range Manage. 39:341-344.

Statement of Ownership, Management, and Circulation

(Act. of August 12, 1970, Sec. 3685, Title 39, United States Code)

1. Title of Publication: Journal of Range Management

2. Date of Filing: September 14, 1987

3. Frequency of Issue: Bimonthly

4. Location of Office of Publication: 1839 York Street., Denver, Colo. 80206

5. Location of General Business Office: Same

6. Name and Address of:

Publisher: Society for Range Management, 1839 York Street., Denver, Colo. 80206

Editor: Patricia Smith 1839 York Street,

Denver, Colo. 80206

Managing Editor: Peter V. Jackson III 1839 York Street,

Denver, Colo. 80206

7. Owner: Society for Range Management, 1839 York Street, Denver, Colo. 80206

8. Known Bondholders, Mortgagees, etc.: None

9. For Completion by Nonprofit Organizations Authorized to Mail at Special Rates: The purpose, function, and nonprofit status of this organization and the exempt status for Federal income tax purposes have not changed during preceding 12 months.

10. Extent and Nature of Circulation
A. Total copies printed
B. Paid Circulation
1. Dealers, counter sales
2. Mail subscriptions
C. Total paid circulation
D. Free distribution
E. Total distribution
F. Copies not distributed
G. Total

\begin{tabular}{rr} 
Avg. for & \multicolumn{2}{c}{ Actual for } \\
issue nearest \\
12 months & $\begin{array}{r}\text { filing date } \\
5,766\end{array}$ \\
& 5,500 \\
0 & 0 \\
5,091 & 5,085 \\
5,091 & 5,085 \\
10 & 10 \\
5,100 & 5,095 \\
666 & 405 \\
5,766 & 5,500
\end{tabular}

I certify that the statements made by me above are correct and complete.-Peter V. Jackson, Managing Editor. 